\title{
Étude sur les variations de la flore lactique et bifide intestinale par rapport à l'administration des cellules lactiques du yaourt
}

\author{
par \\ B. BIANCHI-SALVADORI et M. GOTTI \\ Centro Sperimentale del Latte (Milano) \\ F. BRUGHERA \\ Istituto Ospedaliero Provinciale Maternita' (Milano) \\ et \\ U. POLINELLI \\ Istituto Provinciale Protezione Assistenza Infanzia (Milano)
}

\section{INTRODUCTION}

Il est bien connu $[1,2,3]$ que la composition qualitative de la flore autochtone intestinale possède une physionomie pratiquement stable et typique pour chaque espèce, avec des variations plus ou moins grandes, compte tenu de la pollution habituelle du milieu, à laquelle peut venir s'ajouter une pollution occasionnelle.

Dans ce milieu, la compétitivité intermicrobienne, la capacité immunitaire de l'hôte, les conditions hygiéniques générales et alimentaires, etc. jouent un rôle très important. En dehors de l'interaction de ces conditions de base, l'influence polyvalente de la qualité et de la quantité de l'alimentation demeure l'un des facteurs les plus importants.

Déjà Salvadori $[4,5]$, suite à des recherches polydisciplinaires faites avec notre collaboration, était arrivé à démontrer que les lactobacilles du yaourt survivaient au cours de leur passage à travers tout le tube gastro-entérique.

Cette démonstration se voyait confirmée par la comparaison univoque de recherches différenciées ayant donné des résultats parfaitement identiques $[6,7]$. 
Du reste, la validité de cette observation ne peut être conditionnée par des critiques concernant l'absence d'implantation endointestinale de la flore lactique ; elle met, au contraire, en évidence la fonction d'élément modérateur que chaque type d'alimentation prend à l'égard de la flore autochtone intestinale [8].

Il restait à établir si l'on pouvait attribuer à la survie de la flore lactique du yaourt une capacité modificatrice active, et non seulement passive, quel était le degré de cette capacité présumée et, enfin, si l'on devait considérer l'éventuelle modification produite comme étant utile, indifférente ou nuisible.

\section{BUT DE LA RECHERCHE}

Nos précédentes recherches ont mis en évidence un certain nombre de faits que nous mentionnons synthétiquement ci-après :

a) Les cellules microbiennes du yaourt survivent après l'ingestion, se retrouvent encore dans les selles et sont biologiquement actives.

b) Cette survie est restée inchangée même lorsque les cellules ont été administrées lavées et, par conséquent, non protégées par les micelles de caséine.

c) Le L. bulgaricus et le St. thermophilus ont révélé, in vitro, pouvoir résister à des concentrations d'acide désoxycholique égales à celles que l'on retrouve habituellement dans l'intestin [9].

C'est en partant de ces données que nous avons cru bon d'affronter une fois encore une recherche critique sur le rôle nutritionnel des lactobacilles. Le but de cette recherche a été de perfectionner les expériences précédentes, afin de rechercher les éventuelles interactions microbiennes produites, dans le cadre de l'équilibre microécologique de l'appareil digestif, par les cellules lactiques administrées, de façon à en établir la véritable importance dans le cadre de l'alimentation en général.

\section{MATERIAUX ET METHODES}

Les souches utilisées pour cette recherche ont été isolées de cultures de yaourts du commerce et identifiées en tant que Lactobacillus bulgaricus et Streptococcus thermophilus grâce aux méthodes habituelles de classification [10] et par la micro-méthode API system 50 L [11].

Nous avons choisi des souches à activité acidifiante plus élevée, qui ont été inoculées respectivement dans 51 de bouillon MRS [12] 
(L. bulgaricus) et dans 51 de bouillon séro-peptoné (St. thermophilus), et mises en incubateur à $45^{\circ} \mathrm{C}$ pendant $15 \mathrm{~h}$ [13].

Les cellules, recueillies par centrifugation et lavées deux fois dans une solution physiologique, afin d'en faire disparaître toute trace de milieu de culture, ont été mises en suspension dans $12 \mathrm{ml}$ de solution physiologique, dans le rapport 1:1 (coques et bâtonnets), à raison de 100 milliards pour chaque part (quantité de cellules correspondant à celles se trouvant dans un petit pot de yaourt de $125 \mathrm{~g})$.

Une partie de la suspension a été soumise à pasteurisation $\left(90^{\circ} \mathrm{C} \times 30 \mathrm{mn}\right)$ et utilisée pour les essais de contrôle.

Les suspensions de ferments lactiques étaient produites tous les $2 \mathrm{j}$ et conservées à $+45^{\circ} \mathrm{C}$, jusqu'au moment de leur administration.

Les cellules des ferments lactiques ont été administrées à des enfants âgés de 3 à 20 mois, avant le dernier repas du soir et pendant $15 \mathrm{j}$ consécutifs. Les enfants choisis ne présentaient aucune maladie ni troubles de l'appareil digestif ; leur alimentation et leur âge sont rapportés dans le tableau 1. On a administré à neuf enfants des suspensions de cellules lactiques vivantes ; à deux autres, des suspensions contenant des cellules détruites par la chaleur (contrôle).

L'appétibilité s'est avérée bonne et il n'a été relevé aucun cas d'intolérance.

Nous avons recueilli les toutes premières selles, qui ont été évacuées le lendemain même de l'administration. Le prélèvement a été effectué au moyen d'une sonde stérile, en éliminant la première partie évacuée. Pour chaque enfant, on a effectué quatre prélèvements, ainsi distribués :

a) Avant l'alimentation avec des ferments lactiques.

b) Après $7 \mathrm{j}$ d'alimentation avec des ferments lactiques.

c) Après $14 \mathrm{j}$ d'alimentation avec des ferments lactiques.

d) $7 \mathrm{j}$ après la suspension de l'administration.

Parallèlement, sur le deuxième groupe d'enfants, on a poursuivi le traitement avec des cellules détruites par la chaleur (contrôle).

Les selles, recueillies stérilement, ont été immédiatement soumises à l'analyse. L'examen organoleptique et le $\mathrm{pH}$ ont été effectués sur une partie de l'échantillon ; la partie restante a été diluée dans une solution physiologique stérile (bouillie immédiatement avant l'emploi).

La suspension a été homogénéisée, au moyen d'une baguette stérile, délicatement, afin que l'oxygène ne puisse pas s'incorporer à la masse. 
Pour les dilutions successives constantes $(1: 10)$, on a procédé aux déterminations ci-après :

- activité dans le lait, selon la méthode décrite dans de précédents travaux [5];

- contrôle direct de la présence de $E$. coli entéropathogène, selon la méthode par immunofluorescence [10] ;

- dénombrement total des germes anaérobies sur milieu VF [10], incubation à $37^{\circ} \mathrm{C}$ pendant $48 \mathrm{~h}$, dans des conditions d'anaérobie et sur milieu VF, additionné de néomycine [14] dans le but d'éviter le développement des entérobactéries), incubation à $37^{\circ} \mathrm{C}$ pendant $48 \mathrm{~h}$ dans les conditions d'anaérobie;

- dénombrement des entérobactéries en milieu Mossel [15], incubation à $32^{\circ} \mathrm{C}$ pendant $24 \mathrm{~h}$, et en bouillon lactosé bilié au vert brillant avec incubation à $37^{\circ} \mathrm{C}$ pendant $48 \mathrm{~h}$ : sur les éprouvettes positives, il a été effectué le test de Mc Kenzie [10] ;

- dénombrement des streptocoques fécaux, par l'emploi du milieu de Rothe, repiquage en bouillon Litski et confirmation sur Agar Barnes [10] ;

- dénombrement des ferments lactiques mésophiles par dilutions successives dans du lait, en triple, et numérotage du NPP, suivant le tableau de Mac Crady [16], et sur terrains solides, tels que MRS [12], SL [17], séro-peptone (SP) [13], incubation à $30^{\circ} \mathrm{C}$ pendant $72 \mathrm{~h}$. Les milieux solides ont été incubés en atmosphère d'azote +10 p. 100 de $\mathrm{CO}_{2}$;

- dénombrement des ferments lactiques thermophiles par dilutions successives dans du lait, en triple et numérotage du NPP, suivant le tableau de Mac Crady [16], et sur milieux solides, tels que séro-peptone Agar et lait cuit [17], incubation à $45^{\circ} \mathrm{C}$ pendant $24 \mathrm{~h}$;

- sur cinq sujets, l'on a en outre effectué le dénombrement des bifidobactéries en milieu PTG Agar et PTG bouillon [18], incubation à $37^{\circ} \mathrm{C}$ pendant $5 \mathrm{j}$ en atmosphère de $\mathrm{CO}$. Afin de pouvoir établir le nombre des formes bifides présentes, l'on a effectué l'identification microscopique des colonies qui se sont développées dans les plaques de PTG, aux dilutions les plus élevées. Nous avons procédé à un contrôle microscopique identique sur les dilutions en bouillon.

Des plaques des milieux solides utilisés pour le dénombrement des ferments lactiques, l'on a effectué des isolements en vue de l'identification des espèces présentes. Sur les cultures en milieu liquide, grâce à un contrôle microscopique, nous avons déterminé le rapport entre formes rondes et formes en bâtonnet. Ensuite, nous avons effectué un étalement de chaque dilution sur milieu agarisé (MRS, SP, SL), dans le but d'isoler le plus grand nombre de colonies en vue de l'identification des formes lactiques présentes.

Pour l'identification des souches isolées, nous avons utilisé la micro-méthode API system $50 \mathrm{~L}$ [11]. 


\section{RESULTATS}

Dans les tableaux et sur les graphiques sont représentés les résultats concernant les valeurs du $\mathrm{pH}$, de l'acidité qui s'est dégagée dans le repiquage dans le lait (activité), le dénombrement des divers groupes microbiens relevés dans les selles des enfants alimentés avec des cellules de L. bulgaricus et St. thermophilus lavées, pasteurisées et vitales, ainsi que les résultats des analyses statistiques.

TABLEAU 1

\begin{tabular}{|c|c|c|c|c|}
\hline & & Age & Sexe & Diète \\
\hline $\mathrm{N}^{\circ}$ & 1 & 6 mois & M & Bouillie douce : \\
\hline & 2 & 9 mois & M & $\begin{array}{l}250 \mathrm{~g} \text { de lait de vache }+50 \mathrm{~g} \text { d'eau } \\
+ \text { une cuillère de sucre }+ \text { decoriso }(1) \text {. }\end{array}$ \\
\hline $\mathrm{N}^{\circ}$ & 3 & 6 mois & F & \\
\hline $\mathrm{N}^{\circ}$ & 4 & 6 mois & F & \\
\hline $\mathrm{N}^{\circ}$ & 5 & 6 mois & M & Potage aux herbes : \\
\hline $\mathrm{N}^{\circ}$ & 6 & 3 mois & $\mathrm{F}$ & $250 \mathrm{~g}$ de bouillon végétal + deux à \\
\hline $\mathrm{N}^{\circ}$ & 7 & 20 mois & $\mathrm{F}$ & $\begin{array}{l}\text { petites cuillères d'homogénéisé de } \\
\text { viande. }\end{array}$ \\
\hline $\mathrm{N}^{\circ}$ & 8 & 4 mois & M & \\
\hline & 9 & 7 mois & $\mathrm{F}$ & \\
\hline $\mathrm{N}^{\circ}$ & 10 & 7 mois & M & \\
\hline $\mathrm{N}^{0}$ & 11 & 5 mois & $\mathrm{F}$ & \\
\hline
\end{tabular}

(1) Crème de poudre de riz (aliment pour nourrissons).

\section{a) Enfants alimentés avec des cellules lavées et pasteurisées}

- le $\mathrm{pH}$ est compris entre les valeurs 6 et 8 , les activités dans le lait sont irrégulières et ne sont pas significatives (tab. 2) ;

- le nombre total des germes anaérobies se maintient donc à des niveaux à peu près constants tout le long de l'expérience ; 
TABLEAU 2

Valeurs du pH et de l'activité (contrôle)

\begin{tabular}{l|c|c|c|c|c}
\hline & & $\mathrm{A}$ & $\mathrm{B}$ & $\mathrm{C}$ & $\mathrm{D}$ \\
\hline \multirow{2}{*}{$\mathrm{N}^{\circ} 10$} & $\mathrm{pH}$ & 8.17 & 8.28 & 8.42 & 7.98 \\
& activité* & 0.85 & 0.98 & 0.71 & 1.32 \\
\hline \multirow{2}{*}{$\mathrm{N}^{\circ} 11$} & $\mathrm{pH}$ & 5.90 & 7.20 & 6.60 & 7.02 \\
\cline { 3 - 4 } & activité & 0.81 & 1.00 & 1.07 & 1.90 \\
\hline
\end{tabular}

* = en p. 100 d'acide lactique.

- les entérobactéries, tout comme les germes totaux, ne présentent pas de variations numériques importantes, tout le long de l'expérience, l'E. coli entéro-pathogène a toujours été absente ;

- les streptocoques fécaux sont représentés par les espèces St. durans, faecium et faecalis;

- le St. thermophilus se maintient à des niveaux constants dans tous les prélèvements;

- les streptocoques mésophiles et les lactobacilles présentent une évolution irrégulière tout au long de l'expérience. Les souches isolées se rapportent aux espèces : L. casei et L. fermenti (fig. 1 et 2).

\section{b) Enfants alimentés avec des cellules lavées et vitales}

- le $\mathrm{pH}$ a des valeurs comprises entre 6 et 8 et, chez certains sujets, il subit une diminution durant la durée du traitement (tab. 3) ;

- en tenant compte qu'il existe de grandes différences numériques entre les divers individus, le nombre total des germes anaérobies se maintient à un niveau compris entre 100 millions et 10 milliards pendant toute la durée de l'expérience (fig. 3) ;

- l'évolution numérique des entérobactéries est, dans ses lignes générales identique à celle du nombre microbien total anaérobien. Dans les selles, on n'a jamais trouvé de traces d'E. coli entéro-pathogènes (fig. 4);

- les streptocoques fécaux présentent, tout au long de l'expérience, une évolution irrégulière, en se maintenant, en ligne générale, 


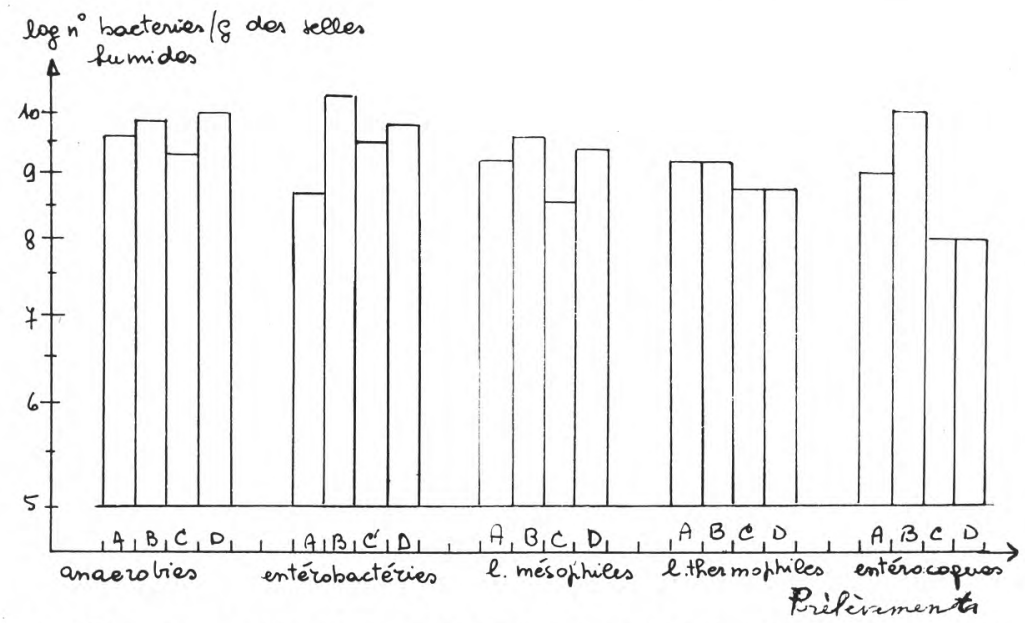

$\mathrm{A} B C \mathrm{D}=$ avant, durant et après l'administration des ferments lactiques.

fig. 1

Histogramme des résultats du premier contrôle

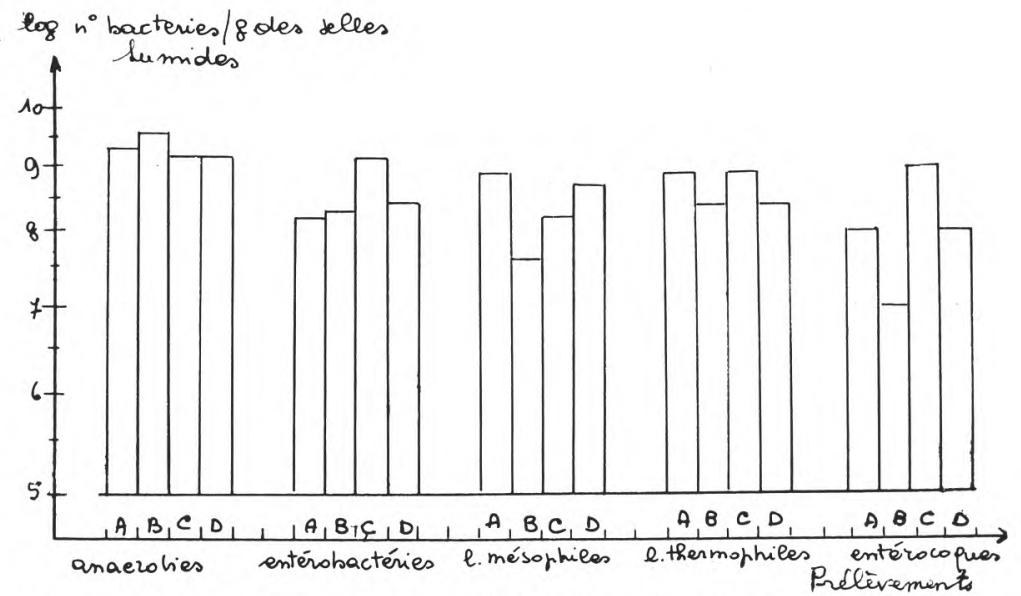

$\mathrm{A} B C \mathrm{D}=$ avant, durant et après l'administration des ferments lactiques.

fig. 2

Histogramme des résultats du deuxième contrôle 
TABLEAU 3

Valeurs du pH et de l'activité

\begin{tabular}{|c|c|c|c|c|c|}
\hline & & A & B & C & D \\
\hline $\mathrm{N}^{\circ} 1$ & $\begin{array}{c}\mathrm{pH} \\
\text { activité* }\end{array}$ & $\begin{array}{l}6.34 \\
0.65\end{array}$ & $\begin{array}{l}\text { n.d. } \\
0.85\end{array}$ & $\begin{array}{l}6.44 \\
0.64\end{array}$ & $\begin{array}{l}5.68 \\
\text { n.d. }\end{array}$ \\
\hline $\mathrm{N}^{\circ} 2$ & $\begin{array}{c}\mathrm{pH} \\
\text { activité }\end{array}$ & $\begin{array}{l}6.04 \\
0.88\end{array}$ & $\begin{array}{l}\text { n.d. } \\
0.88\end{array}$ & $\begin{array}{l}6.42 \\
0.51\end{array}$ & $\begin{array}{l}6.50 \\
0.49\end{array}$ \\
\hline $\mathrm{N}^{\circ} 3$ & $\begin{array}{c}\mathrm{pH} \\
\text { activité }\end{array}$ & $\begin{array}{l}4.97 \\
0.86\end{array}$ & $\begin{array}{l}\text { n.d. } \\
0.70\end{array}$ & $\begin{array}{l}5.59 \\
0.68\end{array}$ & $\begin{array}{l}6.10 \\
\text { n.d. }\end{array}$ \\
\hline $\mathrm{N}^{\circ} 4$ & $\begin{array}{c}\mathrm{pH} \\
\text { activité }\end{array}$ & $\begin{array}{l}6.32 \\
0.66\end{array}$ & $\begin{array}{l}\text { n.d. } \\
0.70\end{array}$ & $\begin{array}{l}4.98 \\
0.61\end{array}$ & $\begin{array}{l}5.61 \\
0.75\end{array}$ \\
\hline $\mathrm{N}^{\circ} 5$ & $\begin{array}{c}\mathrm{pH} \\
\text { activité }\end{array}$ & $\begin{array}{l}6.39 \\
0.70\end{array}$ & $\begin{array}{l}\text { n.d. } \\
0.65\end{array}$ & $\begin{array}{l}5.48 \\
0.55\end{array}$ & $\begin{array}{l}5.77 \\
0.90\end{array}$ \\
\hline $\mathrm{N}^{\circ} 6$ & $\begin{array}{c}\mathrm{pH} \\
\text { activité }\end{array}$ & $\begin{array}{l}8.29 \\
0.58\end{array}$ & $\begin{array}{l}7.74 \\
1.38\end{array}$ & $\begin{array}{l}7.80 \\
0.91\end{array}$ & $\begin{array}{l}8.89 \\
0.89\end{array}$ \\
\hline $\mathrm{N}^{\circ} 7$ & $\begin{array}{c}\mathrm{pH} \\
\text { activité }\end{array}$ & $\begin{array}{l}8.48 \\
0.47\end{array}$ & $\begin{array}{l}8.29 \\
1.00\end{array}$ & $\begin{array}{l}7.67 \\
1.10\end{array}$ & $\begin{array}{l}8.30 \\
1.20\end{array}$ \\
\hline $\mathrm{N}^{\circ} 8$ & $\begin{array}{c}\mathrm{pH} \\
\text { activité }\end{array}$ & $\begin{array}{l}7.05 \\
0.90\end{array}$ & $\begin{array}{l}5.94 \\
0.88\end{array}$ & $\begin{array}{l}7.31 \\
0.89\end{array}$ & $\begin{array}{l}7.09 \\
0.80\end{array}$ \\
\hline $\mathrm{N}^{\circ} 9$ & $\begin{array}{c}\mathrm{pH} \\
\text { activité }\end{array}$ & $\begin{array}{l}8.11 \\
0.65\end{array}$ & $\begin{array}{l}7.06 \\
1.20\end{array}$ & $\begin{array}{l}8.18 \\
1.00\end{array}$ & $\begin{array}{l}7.25 \\
0.70\end{array}$ \\
\hline
\end{tabular}

* = en p. 100 d'acide lactique. 


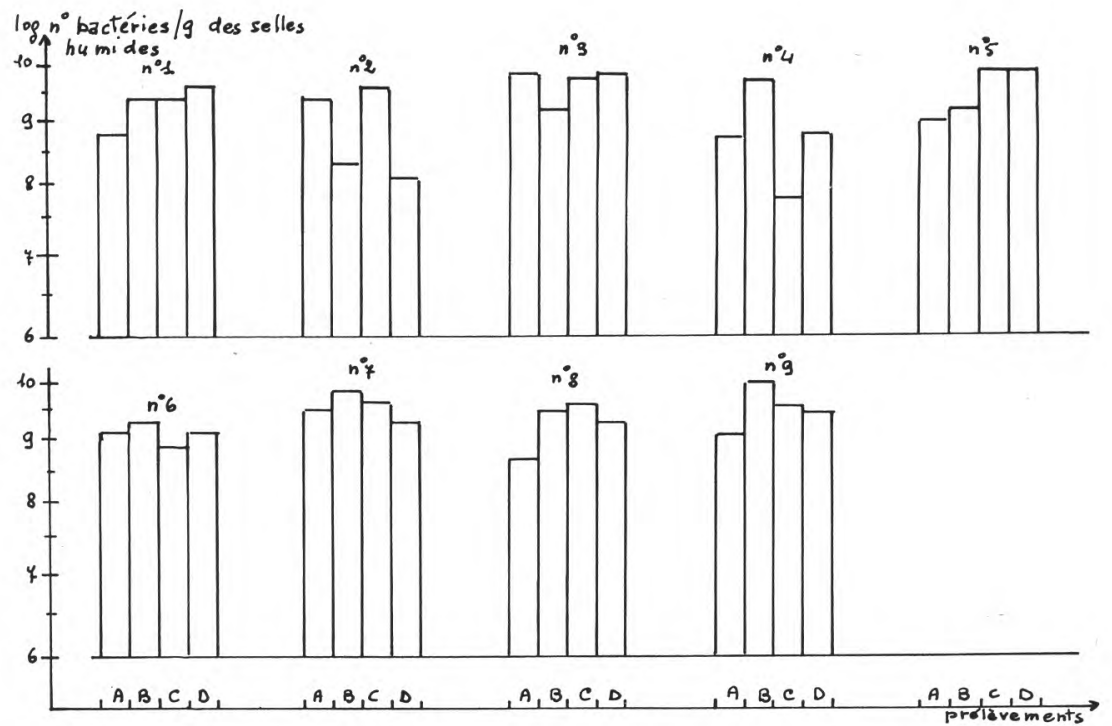

$N^{\text {os }} 1,2,3 \ldots=$ enfants examinés.

$\mathrm{A} B C \mathrm{D}=$ avant, durant et après l'administration des ferments lactiques.

fig. 3

Histogramme du nombre des germes anaérobies

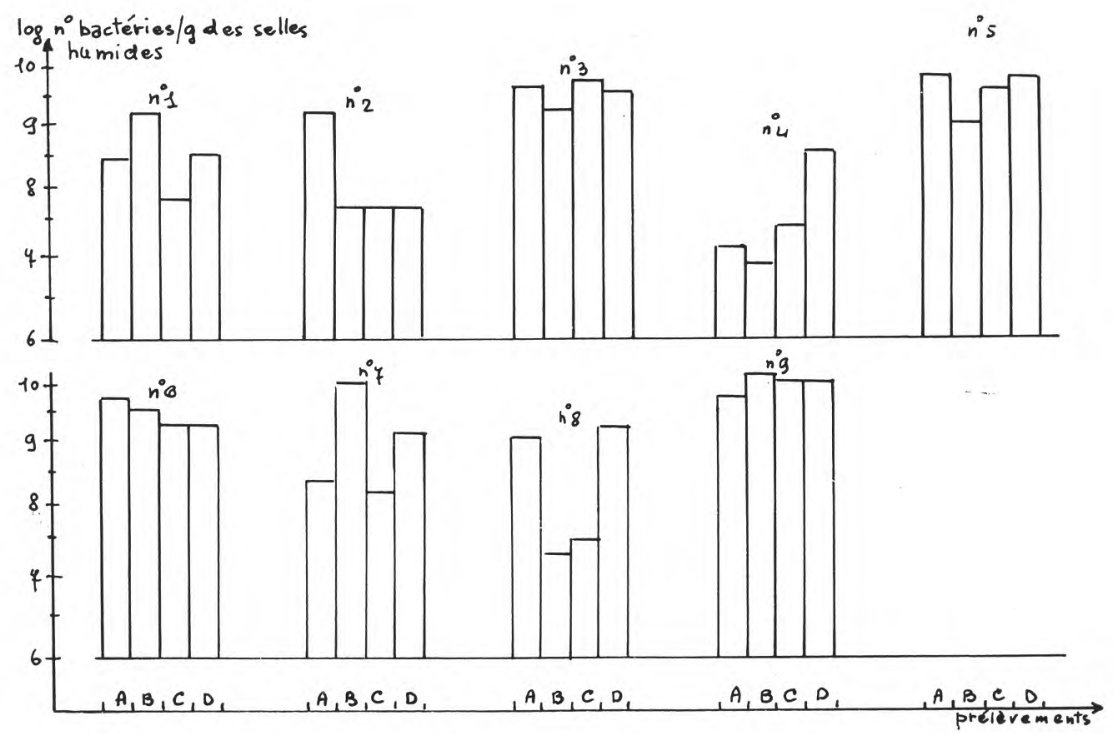

$\mathrm{N}^{\circ \mathrm{s}} 1,2,3 \ldots=$ enfants examinés.

$\mathrm{A} B C \mathrm{D}=$ avant, durant et après l'administration des ferments lactiques.

fig. 4

Histogramme du nombre des entérobactéries 


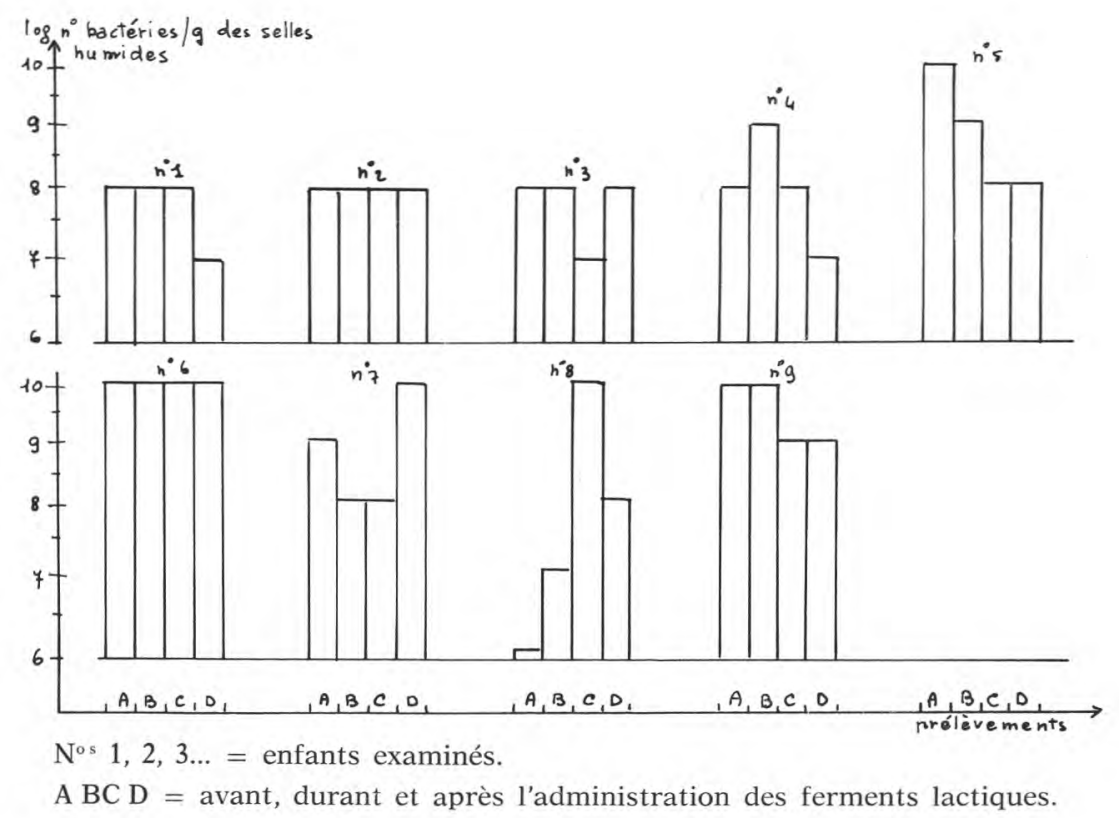

fig. 5

Histogramme du nombre des entérobactéries

à des niveaux inférieurs par rapport au nombre microbien total des anaérobies chez certains sujets; les souches relevées sont du genre St. durans et St. faecium (fig. 5).

En ce qui concerne la flore lactique mésophile et thermophile, le résultat le plus intéressant, c'est que l'on retrouve dans les selles, les espèces lactiques administrées. En effet, les espèces retrouvées, attribuables au genre Lactobacillus sont : L. acidophilus, L. lactis, L. bulgaricus, L. casei, L. fermenti ; celles attribuables au genre Streptococcus : St. lactis et St. thermophilus (fig. 6 et 7).

En ce qui concerne les espèces microbiennes lactiques non diagnosticables selon les méthodes habituelles, l'on a eu recours à la méthode de Sneath et Sokal; qui a donné le résultat suivant : regroupement de coques et de bâtonnets suivant des aspects taxonomiquement homogènes.

Profils moyens des sept groupes définis dans le schéma :

Ces profils ne s'adaptent bien à aucune espèce définie, à l'exception du groupe $\mathrm{n}^{\circ} 3$, qui correspond à l'espèce $L$. bulgaricus. Le 


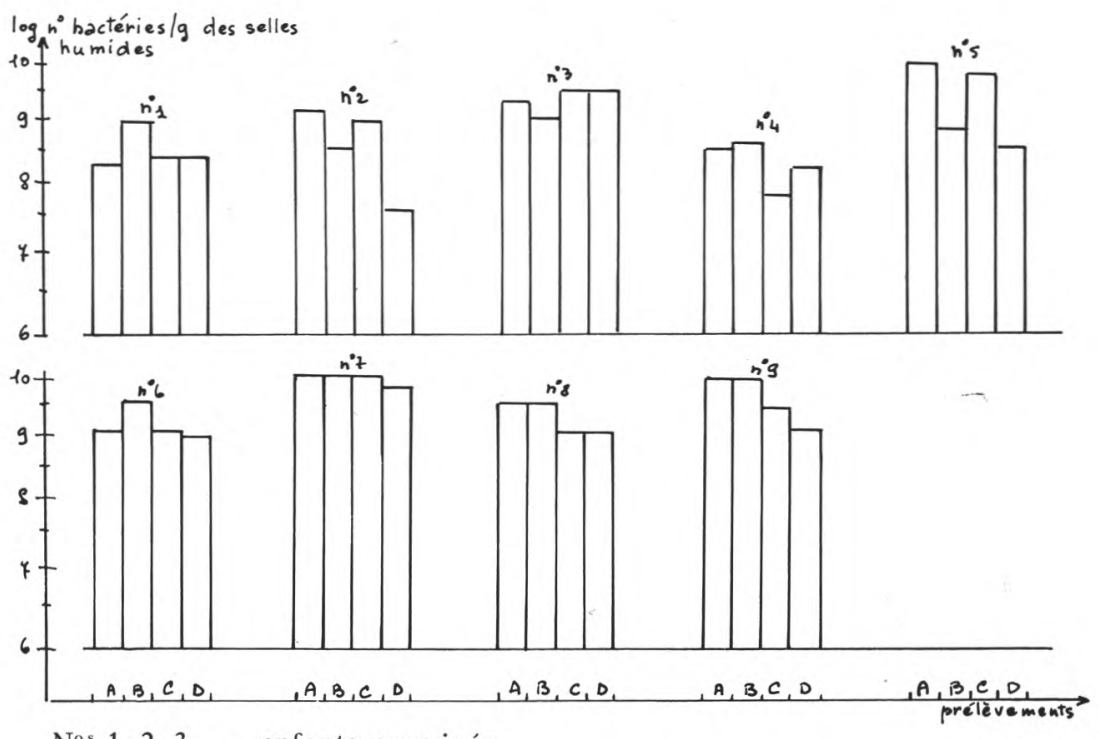

$\mathrm{N}^{\text {os }} 1,2,3 \ldots=$ enfants examinés.

$\mathrm{A} B C \mathrm{D}=$ avant, durant et après l'administration des ferments lactiques.

Fig. 6

Histogramme du nombre des bactéries lactiques mésophiles

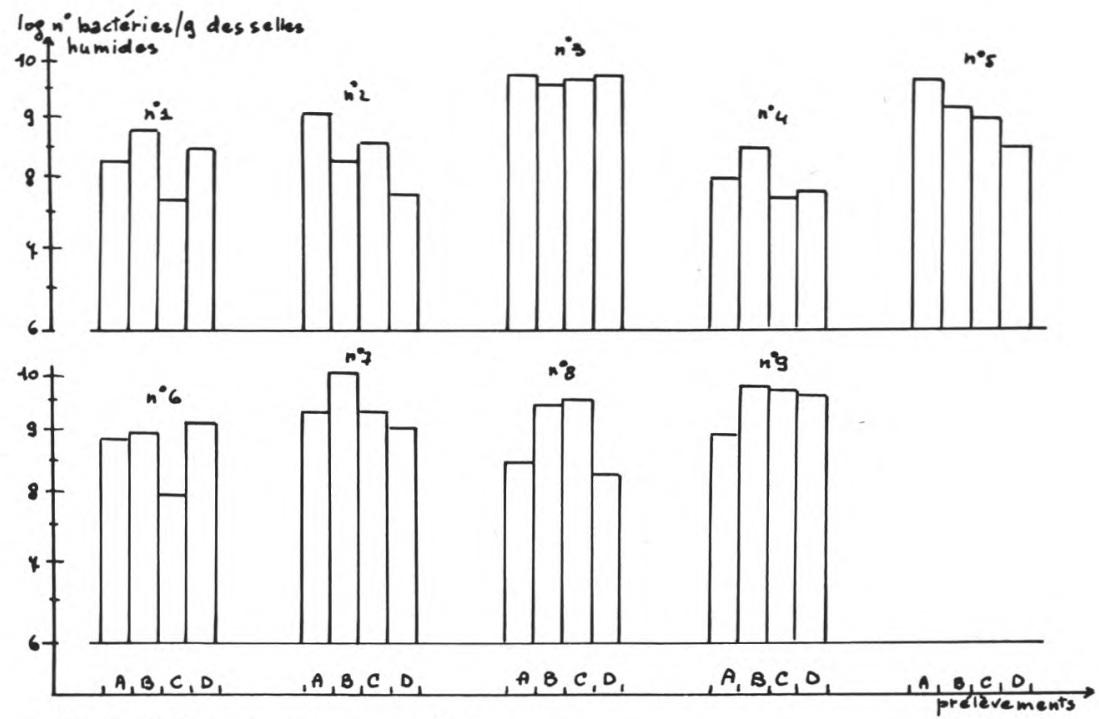

$\mathrm{N}^{\mathrm{s}} 1,2,3 \ldots=$ enfants examinés.

A BC D = avant, durant et après l'administration des ferments lactiques.

fig. 7

Histogramme du nombre des bactéries lactiques thermophiles 
groupe $\mathrm{n}^{\circ} 1$, le plus important par le grand nombre de souches qu'il comprend, est constitué, en général, par des coques et par quelques bâtonnets ; c'est un groupe très dense, ayant des liens assez rapprochés ; les autres groupes semblent être des atypiques du premier groupe.

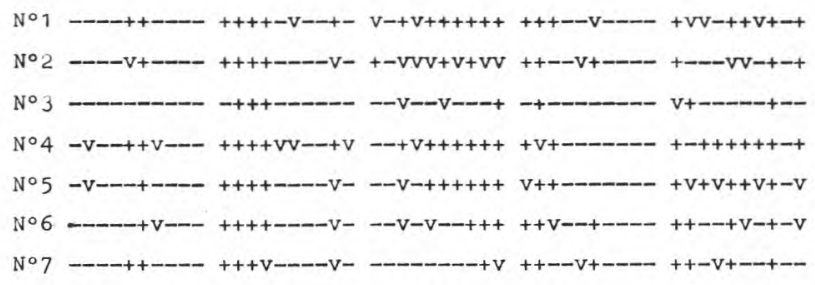

Le critère de ressemblance, utilisé pour approcher deux aspects, est celui de la distance euclidienne, calculée dans un espace à 50 dimensions (fig. 8).

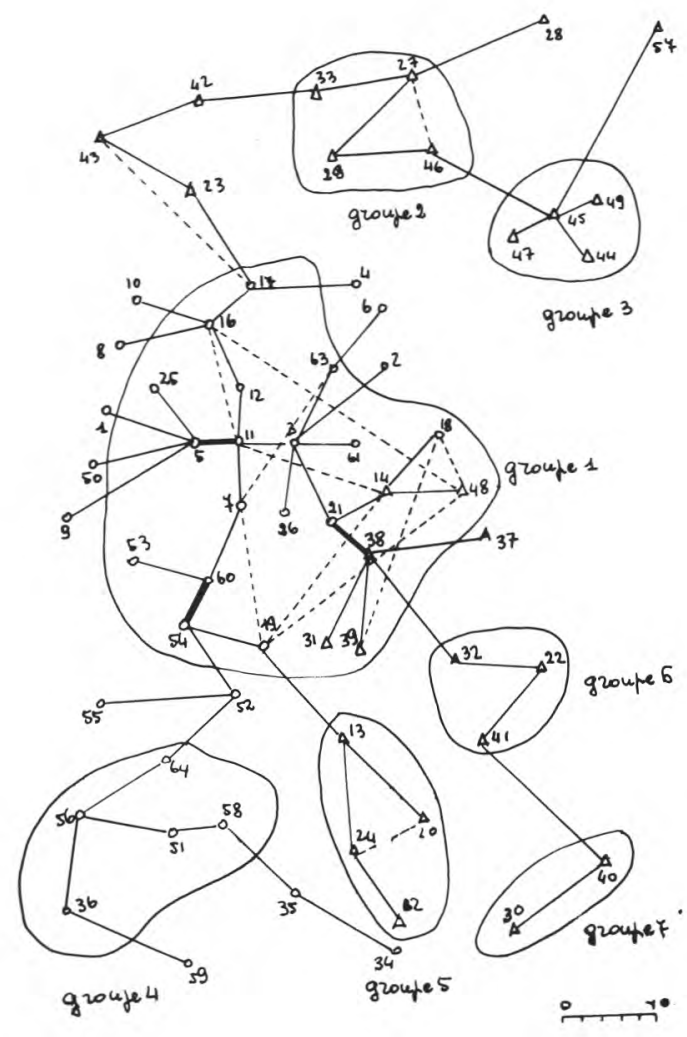

fig. 8

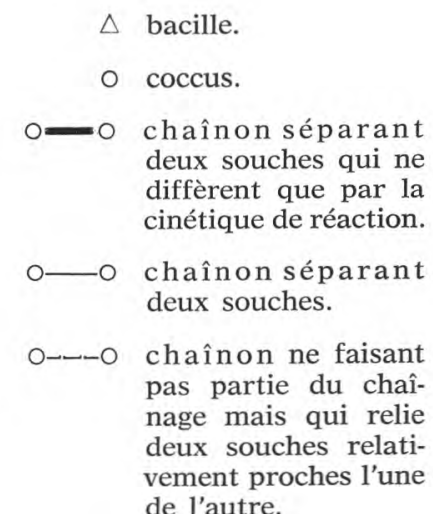
de l'autre. 
A chaque souche correspond un point de cet espace, dont les coordonnées sont les valeurs obtenues pour chacun des cinquante tests de la galerie API $50 \mathrm{~L}$ (tab. 11).

Ce travail de classification a été effectué aux Laboratoires API de Lyon*.

En ce qui concerne la flore bifide, l'on observe une augmentation numérique durant la période d'administration des cellules lactiques (fig. 9).

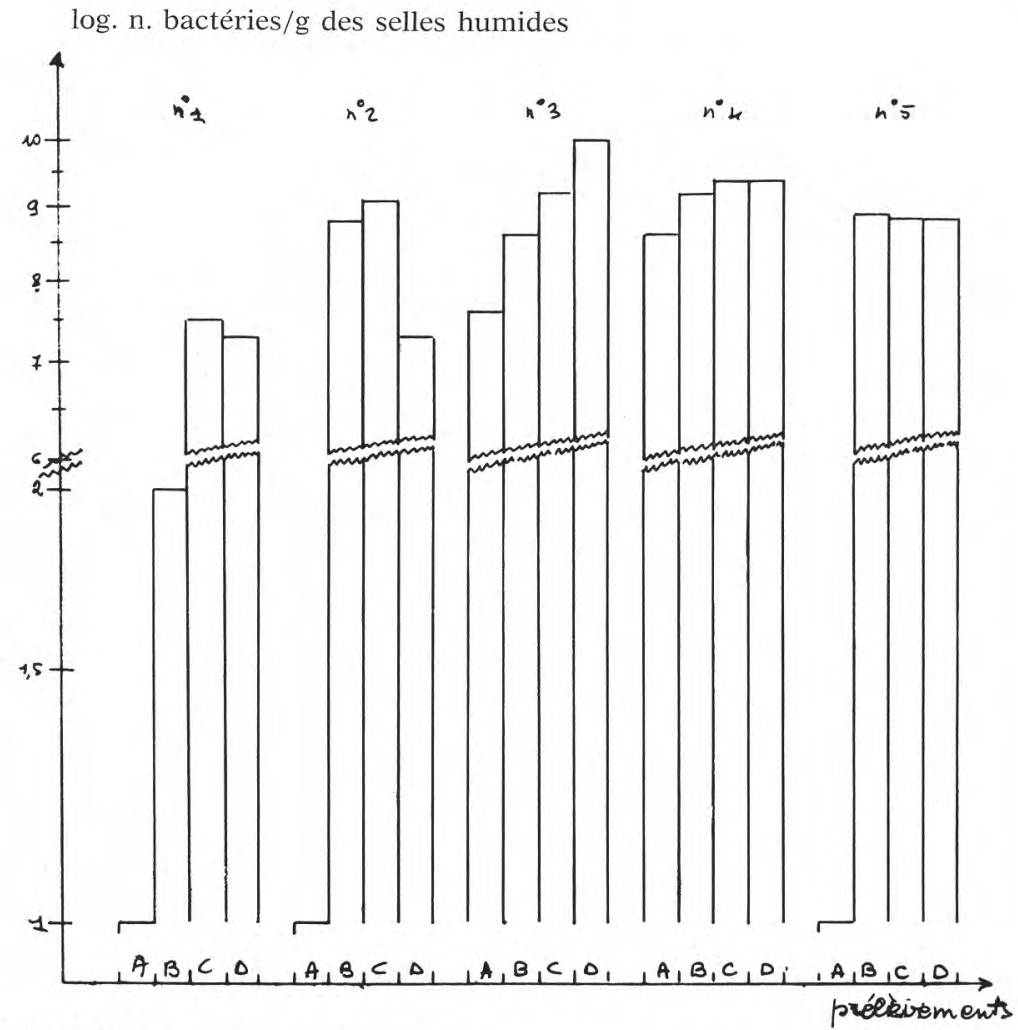

$\mathrm{N}^{\circ} 1,2,3 \ldots=$ enfants examinés.

$\mathrm{A} B C \mathrm{D}=$ avant, durant et après l'administration des ferments lactiques.

fig. 9

Histogramme du nombre des bifidobactéries

\footnotetext{
* Nous tenons à remercier M. Laban qui a bien voulu effectuer ce travail d'analyse mathématique sur les données biochimiques des souches de ferments lactiques isolés par les selles.
} 


\section{ANALYSE STATISTIQUE}

Il a été effectué une analyse statistique sur le log du nombre total des germes anaérobies, de la flore lactique mésophile et thermophile, des entérobactéries et des bifidobactéries des sujets alimentés avec des cellules "vivantes ».

A l'exception des bifidobactéries, pour l'analyse desquelles l'on disposait de données recueillies sur cinq sujets, dans tous les autres cas, l'analyse statistique a été effectuée sur des données tirées des expériences effectuées sur tous les neuf sujets.

L'analyse de la variance, par schémas synoptiques, a mis en évidence les caractéristiques suivantes :

- le nombre total des germes anaérobies n'est pas influencé par le traitement (tab. 4); il en va de même pour les entérobactéries (tab. 5) ;

- la flore lactique mésophile subit des modifications assez importantes durant la période d'administration des ferments lactiques du yoghourt ( $P=0,025)$ (tab. 6) ;

- la flore lactique thermophile subit des variations très importantes $(P=0,01)$ (tab. 7) ;

- les bifidobactéries présentent, entre les traitements, des différences assez importantes $(\mathrm{P}=0,025)$ (tab. 8).

Enfin, vu que l'analyse statistique des entérobactéries (tab. 5) a démontré que ces micro-organismes ne sont pas influencés par l'administration des ferments lactiques du yaourt, on a essayé d'évaluer les rapports numériques existant entre la flore lactique (mésophile et thermophile) et la flore entérobactérienne, en considérant cette dernière comme paramètre fixe par rapport à tous les autres groupes microbiologiques (fig. 10 et 11).

En confirmation des données ainsi obtenues, les analyses de la variance effectuées sur ces rapports résultent :

- très significatives dans le cas du rapport lactiques mésophiles / entérobactéries ;

- et significative en ce qui concerne le rapport lactiques thermophiles / entérobactéries (tab. 9 et 10).

\section{CONCLUSIONS}

L'analyse des résultats des déterminations microbiologiques, par nous effectuées sur les sujets traités avec les ferments lactiques du yaourt ( $L$. bulgaricus et $S t$. thermophilus) a confirmé les résultats 


\section{TABLEAU 4}

Analyse de la variance effectuée sur les données concernant le nombre microbien total anaérobie

\begin{tabular}{|c|c|c|c|c|c|}
\hline Bloqués (1) & $X_{A}$ & $\mathrm{X}_{\mathrm{B}}$ & $\mathrm{X}_{\mathrm{C}}$ & $X_{D}$ & $(\Sigma X)^{2} / 4$ \\
\hline $1^{\circ}$ & 8.84 & 9.38 & 9.49 & 9.57 & 347.75 \\
\hline $2^{\circ}$ & 9.39 & 8.39 & 9.60 & 8.17 & 316.37 \\
\hline $3^{\circ}$ & 10.00 & 8.30 & 9.92 & 10.04 & 366.18 \\
\hline $4^{\circ}$ & 8.85 & 8.84 & 7.90 & 8.97 & 299.00 \\
\hline $5^{\circ}$ & 9.17 & 9.43 & 10.09 & 10.60 & 386.24 \\
\hline $6^{\circ}$ & 9.07 & 9.30 & 8.95 & 9.07 & 331.48 \\
\hline $7^{\circ}$ & 9.54 & 9.95 & 9.69 & 9.30 & 370.52 \\
\hline $8^{\circ}$ & 8.67 & 9.54 & 9.56 & 9.30 & 343.83 \\
\hline $9^{\circ}$ & 9.04 & 10.04 & 9.59 & 9.47 & 363.87 \\
\hline$\Sigma \mathrm{X}$ & 82.62 & 83.19 & 84.83 & 84.53 & $\Sigma \Sigma X=335.2$ \\
\hline$(\Sigma X)^{2} / 9$ & 758.55 & 769.65 & 799.66 & 794.02 & \\
\hline
\end{tabular}

\begin{tabular}{l|c|c|c|c}
\hline Sources de variation & $\begin{array}{c}\text { Somme des } \\
\text { carrés }\end{array}$ & DDL & Variances & F \\
\hline Total & 11.03 & 35 & & \\
Entre bloqués (2) & 4.35 & 8 & 0.54 & 2.07 n.s. \\
Entre traitements & 0.37 & 3 & 0.12 & 0.48 n.s. \\
Erreur & 6.29 & 24 & 0.26 & \\
\hline
\end{tabular}

(1) Regroupement des quatre traitements de chaque enfant.

$\mathrm{X}_{\mathrm{A}}, \mathrm{X}_{\mathrm{B}}, \mathrm{X}_{\mathrm{C}}, \mathrm{X}_{\mathrm{D}}=$ prélèvements.

(2) Comparaison entre les regroupements des quatre traitements de tous les enfants examinés. 


\section{TABLEAU 5}

Analyse de la variance effectuée sur les données concernant les entérobactéries

\begin{tabular}{c|c|c|c|c|c}
\hline Bloqués (1) & $\mathrm{X}_{\mathrm{A}}$ & $\mathrm{X}_{\mathrm{B}}$ & $\mathrm{X}_{\mathrm{C}}$ & $\mathrm{X}_{\mathrm{D}}$ & $(\Sigma \mathrm{X})^{2} / 4$ \\
\hline & & & & \\
\hline $\mathrm{N}^{\circ} 1$ & 8.44 & 9.17 & 7.87 & 8.53 & 289.50 \\
$\mathrm{~N}^{\circ} 2$ & 9.17 & 7.77 & 7.77 & 7.77 & 264.23 \\
$\mathrm{~N}^{\circ} 3$ & 9.84 & 9.23 & 9.92 & 9.72 & 375.08 \\
$\mathrm{~N}^{\circ} 4$ & 7.07 & 6.77 & 7.54 & 8.39 & 222.00 \\
$\mathrm{~N}^{\circ} 5$ & 10.00 & 9.14 & 9.77 & 10.07 & 380.31 \\
$\mathrm{~N}^{\circ} 6$ & 9.81 & 9.65 & 8.79 & 8.77 & 343.05 \\
$\mathrm{~N}^{\circ}$ & 8.39 & 10.07 & 8.17 & 9.25 & 322.35 \\
$\mathrm{~N}^{\circ} 8$ & 9.13 & 7.30 & 7.46 & 9.34 & 276.40 \\
$\mathrm{~N}^{\circ} 9$ & 9.84 & 10.16 & 10.09 & 10.07 & 403.65 \\
$\Sigma \mathrm{X}$ & 81.73 & 79.30 & 77.45 & 81.96 & $2 \Sigma \mathrm{X}=320.4$ \\
$(\Sigma \mathrm{X})^{2} / 9$ & 742.26 & 698.37 & 666.57 & 746.49 & \\
\hline & & & & \\
\hline
\end{tabular}

\begin{tabular}{l|c|c|c|c}
\hline Sources de variation & $\begin{array}{c}\text { Somme des } \\
\text { carrés }\end{array}$ & DDL & Variances & F \\
\hline & 36.68 & 35 & & \\
Total & 23.93 & 8 & 2.99 & $6.40^{*}$ \\
Entre bloqués (2) & 1.53 & 3 & 0.91 & 1.09 n.s. \\
Entre traitements & 11.21 & 24 & 0.51 & \\
Erreur & & & & \\
\end{tabular}

(1) (2) Voir tableau 4.

$\mathrm{X}_{\mathrm{A}}, \mathrm{X}_{\mathrm{B}}, \mathrm{X}_{\mathrm{C}}, \mathrm{X}_{\mathrm{D}}=$ prélèvements.

$*=\mathrm{P}(0,01)$. 
TABLEAU 6

Analyse de la variance effectuée sur les données concernant les bactéries lactiques mésophiles

\begin{tabular}{|c|c|c|c|c|c|}
\hline Bloqués (1) & $\mathrm{X}_{\mathrm{A}}$ & $\mathrm{X}_{\mathrm{B}}$ & $\mathrm{X}_{\mathrm{C}}$ & $X_{D}$ & $(\Sigma X)^{2} / 4$ \\
\hline $\mathrm{N}^{\circ} 1$ & 8.34 & 9.02 & 8.46 & 8.38 & 292.65 \\
\hline $\mathrm{N}^{\circ} 2$ & 9.22 & 8.47 & 9.05 & 7.65 & 295.99 \\
\hline $\mathrm{N}^{\circ} 3$ & 9.32 & 8.96 & 9.44 & 9.45 & 345.79 \\
\hline$N^{\circ} 4$ & 8.51 & 8.62 & 7.84 & 8.17 & 274.94 \\
\hline $\mathrm{N}^{\circ} 5$ & 9.97 & 8.84 & 9.76 & 8.44 & 342.86 \\
\hline$N^{\circ} 6$ & 9.14 & 9.65 & 9.14 & 9.07 & 342.70 \\
\hline $\mathrm{N}^{\circ} 7$ & 10.14 & 10.14 & 10.01 & 9.90 & 404.20 \\
\hline$N^{\circ} 8$ & 9.65 & 9.65 & 9.14 & 9.14 & 353.41 \\
\hline$N^{\circ} 9$ & 10.14 & 10.14 & 9.65 & 9.17 & 382.62 \\
\hline$\Sigma \mathrm{X}$ & 84.47 & 83.54 & 82.52 & 79.41 & $\Sigma \Sigma X=329.96$ \\
\hline$(\Sigma X)^{2} / 9$ & 792.94 & 775.47 & 756.76 & 700.79 & \\
\hline
\end{tabular}

\begin{tabular}{l|c|c|c|c}
\hline Sources de variation & $\begin{array}{c}\text { Somme des } \\
\text { carrés }\end{array}$ & DDL & Variances & $\mathrm{F}$ \\
\hline & 15.95 & 35 & & \\
Total & 10.84 & 8 & 1.35 & $9.3^{* *}$ \\
Entre bloqués (2) & 1.61 & 3 & 0.53 & $3.6^{*}$ \\
Entre traitements & 3.49 & 24 & 0.14 & \\
Erreur & & & & \\
\hline
\end{tabular}

(1) (2) Voir tableau 4.

$\mathrm{X}_{\mathrm{A}}, \mathrm{X}_{\mathrm{B}}, \mathrm{X}_{\mathrm{C}}, \mathrm{X}_{\mathrm{D}}=$ prélèvements.

$* *=\mathrm{P}(0,01) ; *=\mathrm{P}(0,025)$. 


\section{TABLEAU 7}

Analyse de la variance effectuée sur les données concernant les bactéries lactiques thermophiles

\begin{tabular}{|c|c|c|c|c|c|}
\hline Bloqués (1) & $\mathbf{X}_{\mathrm{A}}$ & $\mathrm{X}_{\mathrm{B}}$ & $\mathbf{X}_{\mathrm{C}}$ & $X_{D}$ & $(\Sigma X)^{2} / 4$ \\
\hline$N^{\circ} 1$ & 8.25 & 8.81 & 7.69 & 8.49 & 276.64 \\
\hline $\mathrm{N}^{\circ} 2$ & 9.13 & 8.32 & 8.63 & 7.84 & 287.93 \\
\hline $\mathrm{N}^{\circ} 3$ & 9.83 & 9.63 & 9.76 & 9.78 & 380.61 \\
\hline $\mathrm{N}^{\circ} 4$ & 8.00 & 8.51 & 7.77 & 7.81 & 257.75 \\
\hline $\mathrm{N}^{\circ} 5$ & 9.74 & 9.25 & 9.01 & 8.55 & 334.38 \\
\hline$N^{\circ} 6$ & 8.91 & 9.03 & 8.07 & 9.25 & 311.57 \\
\hline $\mathrm{N}^{\circ} 7$ & 9.41 & 10.14 & 9.38 & 9.11 & 362.05 \\
\hline $\mathrm{N}^{\circ} 8$ & 8.54 & 9.46 & 9.59 & 8.34 & 322.92 \\
\hline $\mathrm{N}^{\circ} 9$ & 9.05 & 9.88 & 9.78 & 9.75 & 370.08 \\
\hline$\Sigma x$ & 80.90 & 83.08 & 79.72 & 78.95 & $\Sigma \Sigma X=322.6$ \\
\hline$(\Sigma X)^{2} / 9$ & 727.30 & 767.09 & 706.18 & 692.71 & \\
\hline
\end{tabular}

\begin{tabular}{l|c|c|c|c}
\hline Sources de variation & $\begin{array}{c}\text { Somme des } \\
\text { carrés }\end{array}$ & DDL & Variances & F \\
\hline Total & 17.42 & 35 & & \\
Entre bloqués (2) & 1.08 & 8 & 0.13 & 0.70 n.s. \\
Entre traitements & 11.73 & 3 & 3.91 & $20.40^{*}$ \\
Erreur & 4.60 & 24 & 0.19 & \\
& & & & \\
\hline
\end{tabular}

(1) (2) Voir tableau 4.

$\mathrm{X}_{\mathrm{A}}, \mathrm{X}_{\mathrm{B}}, \mathrm{X}_{\mathrm{C}}, \mathrm{X}_{\mathrm{D}}=$ prélèvements.

$*=\mathrm{P}(0,01)$. 


\section{TABLEAU 8}

Analyse de la variance effectuée sur les données concernant les bifidobactéries en PTG

\begin{tabular}{c|c|c|c|c|c}
\hline Bloqués (1) & $\mathrm{X}_{\mathrm{A}}$ & $\mathrm{X}_{\mathrm{B}}$ & $\mathrm{X}_{\mathrm{C}}$ & $\mathrm{X}_{\mathrm{D}}$ & $(\Sigma \mathrm{X})^{2} / 4$ \\
\cline { 2 - 3 } $\mathrm{N}^{\circ} 1$ & 1.00 & 2.00 & 7.47 & 7.30 & 79.01 \\
$\mathrm{~N}^{\circ} 2$ & 1.00 & 8.95 & 9.16 & 7.30 & 174.45 \\
$\mathrm{~N}^{\circ} 3$ & 7.60 & 8.60 & 9.20 & 10.92 & 330.09 \\
$\mathrm{~N}^{\circ} 4$ & 8.65 & 9.17 & 9.47 & 9.47 & 338.25 \\
$\mathrm{~N}^{\circ} 5$ & 1.00 & 8.39 & 8.30 & 8.30 & 169.00 \\
$\Sigma \mathrm{X}$ & 19.25 & 37.13 & 43.62 & 43.30 & \\
& & & & & $\Sigma \Sigma \mathrm{X}=143.31$ \\
$(\Sigma \mathrm{X})^{2} / 5$ & 74.15 & 275.73 & 380.55 & 375.13 & \\
\hline
\end{tabular}

\begin{tabular}{l|c|c|c|c}
\hline Sources de variation & $\begin{array}{c}\text { Somme des } \\
\text { carrés }\end{array}$ & DDL & Variances & F \\
\hline Total & 189.65 & 18 & & \\
Entre bloqués (2) & 78.60 & 4 & 19.65 & $4.58^{*}$ \\
Entre traitements & 63.86 & 3 & 21.28 & $4.96^{*}$ \\
Erreur & 47.18 & 11 & 4.28 & \\
& & & & \\
\hline
\end{tabular}

(1) (2) Voir tableau 4.

$\mathrm{X}_{\mathrm{A}}, \mathrm{X}_{\mathrm{B}}, \mathrm{X}_{\mathrm{C}}, \mathrm{X}_{\mathrm{D}}=$ prélèvements.

* $=\mathrm{P}(0,025)$. 


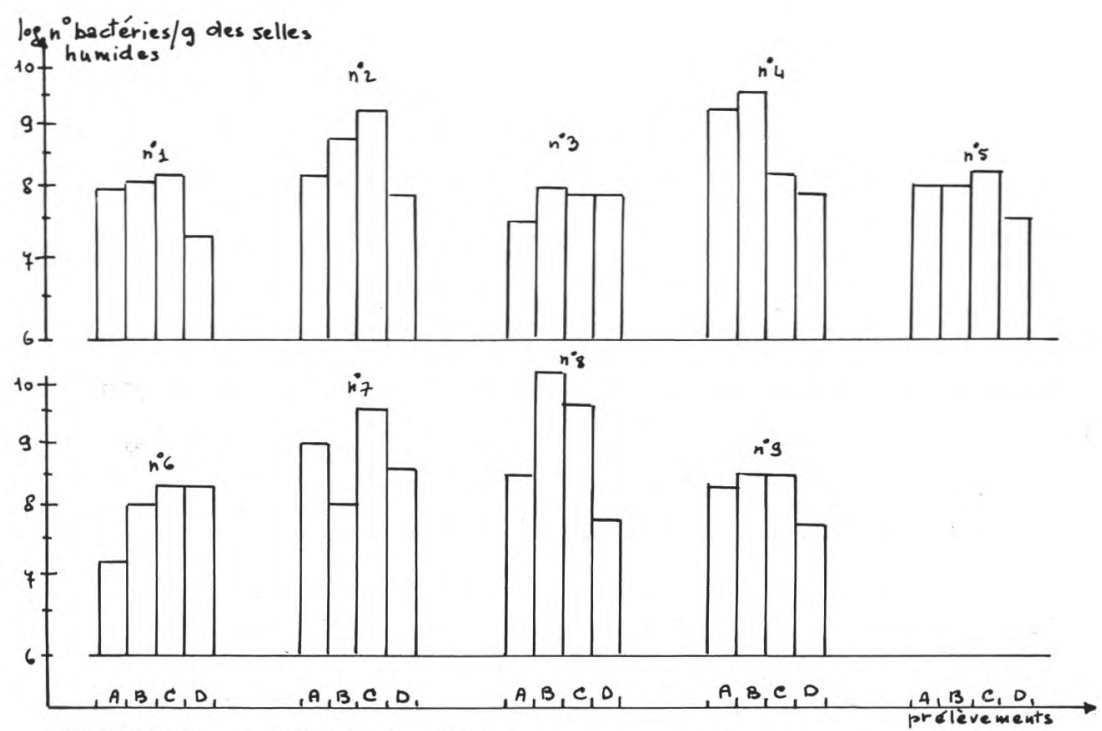

$\mathrm{N}^{\mathrm{s}} 1,2,3 \ldots=$ enfants examinés.

$\mathrm{A} \mathrm{BC} \mathrm{D}=$ avant, durant et après l'administration des ferments lactiques.

fig. 10

Histogramme des rapports numériques entre la flore lactique mésophile et la flore entérobactérienne

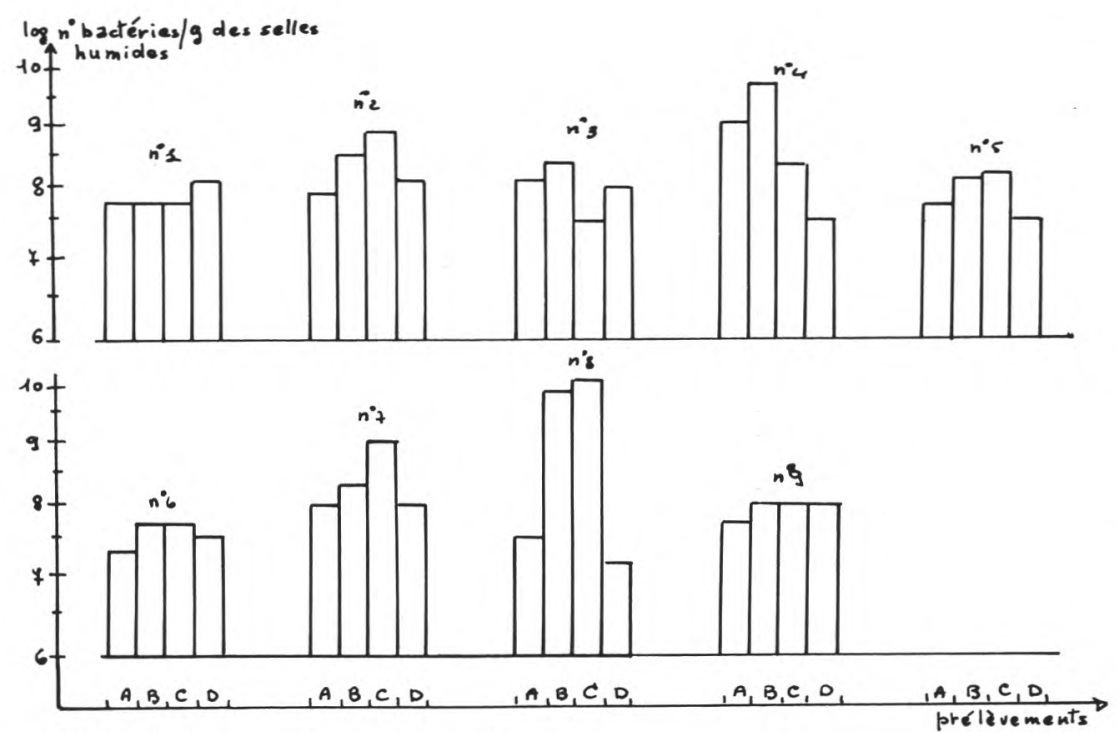

$\mathrm{N}^{\circ} \mathrm{s} 1,2,3 \ldots=$ enfants examinés.

$\mathrm{A} B C \mathrm{D}=$ avant, durant et après l'administration des ferments lactiques.

fig. 11

Histogramme des rapports numériques entre la flore lactique thermophile et la flore entérobactérienne 


\section{TABLEAU 9}

Analyse de la variance effectuée sur les rapports : mésophiles/entérobactéries

\begin{tabular}{|c|c|c|c|c|c|}
\hline Bloqués (1) & $\mathrm{X}_{\mathrm{A}}$ & $\mathrm{X}_{\mathrm{B}}$ & $\mathrm{X}_{\mathrm{C}}$ & $X_{D}$ & $(\Sigma X)^{2} / 4$ \\
\hline $\mathrm{N}^{\circ} 1$ & 7.89 & 7.85 & 8.59 & 7.84 & 258.73 \\
\hline $\mathrm{N}^{\circ} 2$ & 8.04 & 8.69 & 9.27 & 7.87 & 286.8 \\
\hline $\mathrm{N}^{\circ} 3$ & 7.47 & 7.73 & 7.51 & 7.73 & 231.65 \\
\hline $\mathrm{N}^{\circ} 4$ & 9.44 & 9.84 & 8.27 & 7.77 & 311.87 \\
\hline $\mathrm{N}^{\circ} 5$ & 7.97 & 7.69 & 7.98 & 7.36 & 240.25 \\
\hline $\mathrm{N}^{\circ} 6$ & 7.30 & 8.00 & 8.30 & 8.30 & 254.4 \\
\hline $\mathrm{N}^{\circ} 7$ & 9.00 & 8.00 & 9.87 & 8.60 & 314.53 \\
\hline $\mathrm{N}^{\circ} 8$ & 8.51 & 10.35 & 9.69 & 7.79 & 330.15 \\
\hline No 9 & 8.30 & 8.54 & 8.47 & 7.69 & 272.25 \\
\hline$\Sigma \mathrm{X}$ & 73.92 & 76.6 & 77.95 & 70.95 & $\Sigma \Sigma X=299.42$ \\
\hline$(\Sigma \mathrm{X})^{2} / 9$ & 607.13 & 651.95 & 675.13 & 559.32 & $\mathrm{TC}=2490.34$ \\
\hline
\end{tabular}

\begin{tabular}{l|c|c|c|c}
\hline Sources de variation & $\begin{array}{c}\text { Somme des } \\
\text { carrés }\end{array}$ & DDL & Variances & F \\
\hline Total & 22.03 & 35 & & \\
Entre bloqués (2) & 3.19 & 8 & 0.3987 & 1.1199 n.s. \\
Entre traitements & 10.29 & 3 & 3.43 & $9.6348^{*}$ \\
Erreur & 8.55 & 24 & 0.356 & \\
& & & & \\
\hline
\end{tabular}

(1) (2) Voir tableau 4.

$\mathrm{X}_{\mathrm{A}}, \mathrm{X}_{\mathrm{B}}, \mathrm{X}_{\mathrm{C}}, \mathrm{X}_{\mathrm{D}}=$ prélèvements.

* $=\mathrm{P}(0,01)$. 


\section{TABLEAU 10}

Analyse de la variance effectuée sur les rapports : thermophiles/entérobactéries

\begin{tabular}{|c|c|c|c|c|c|}
\hline Bloqués (1) & $\mathrm{X}_{\mathrm{A}}$ & $\mathrm{X}_{\mathrm{B}}$ & $\mathrm{X}_{\mathrm{C}}$ & $X_{D}$ & $(\Sigma X)^{2} / 4$ \\
\hline $\mathrm{N}^{\circ} 1$ & 7.81 & 7.64 & 7.84 & 7.95 & 244.3 \\
\hline $\mathrm{N}^{\circ} 2$ & 7.95 & 8.54 & 8.85 & 8.07 & 279.06 \\
\hline $\mathrm{N}^{\circ} 3$ & 7.99 & 8.39 & 7.84 & 8.06 & 260.50 \\
\hline $\mathrm{N}^{\circ} 4$ & 8.92 & 9.73 & 8.24 & 7.47 & 295.15 \\
\hline $\mathrm{N}^{\circ} 5$ & 7.74 & 8.11 & 8.23 & 7.47 & 248.85 \\
\hline $\mathrm{N}^{\circ} 6$ & 7.30 & 7.69 & 7.69 & 7.47 & 227.25 \\
\hline $\mathrm{N}^{\circ} 7$ & 8.00 & 8.30 & 9.04 & 8.00 & 277.90 \\
\hline $\mathrm{N}^{\circ} 8$ & 7.47 & 9.92 & 10.12 & 7.00 & 297.73 \\
\hline $\mathrm{N}^{\circ} 9$ & 7.69 & 8.00 & 8.00 & 8.00 & 251.06 \\
\hline$\Sigma \mathrm{x}$ & 70.87 & 76.32 & 75.85 & 69.49 & $\Sigma \Sigma X=292.53$ \\
\hline$(\Sigma X)^{2} / 9$ & 558.06 & 647.19 & 639.25 & 536.54 & $\mathrm{TC}=2377.05$ \\
\hline
\end{tabular}

\begin{tabular}{l|c|c|c|c}
\hline Sources de variation & $\begin{array}{c}\text { Somme des } \\
\text { carrés }\end{array}$ & DDL & Variances & F \\
\hline Total & 17.02 & 35 & & \\
Entre bloqués (2) & 4.75 & 8 & 0.59 & 1.735 n.s. \\
Entre traitements & 3.99 & 3 & 1.33 & $3.91^{*}$ \\
Erreur & 8.28 & 24 & 0.34 & \\
& & & & \\
\hline
\end{tabular}

(1) (2) Voir tableau 4.

$\mathrm{X}_{\mathrm{A}}, \mathrm{X}_{\mathrm{B}}, \mathrm{X}_{\mathrm{C}}, \mathrm{X}_{\mathrm{D}}=$ prélèvements.

$*=\mathrm{P}(0,05)$. 
TABLEAU 11

Liste des caractères biochimiques

\begin{tabular}{|c|c|c|}
\hline Substrats & Substrats & Substrats \\
\hline $\begin{array}{l}0 \text { Pourpre de Bromocrésol } \\
1 \text { Glycérol } \\
2 \text { Erythritol } \\
3 \mathrm{~d}(-) \text { arabinose } \\
4 \text { l(+)arabinose } \\
5 \text { Ribose } \\
6 \mathrm{~d}(+) \text { xylose } \\
7 \text { l(-)xylose } \\
8 \text { Adonitol } \\
9 \text { Méthyl-xyloside } \\
10 \text { Galactose } \\
11 \text { d(+)glucose } \\
12 \text { d(-)levulose } \\
13 \text { d(+)mannose } \\
14 \text { l(-) sorbose } \\
15 \text { Rhamnose } \\
16 \text { Dulcitol }\end{array}$ & $\begin{array}{l}17 \text { Méso-inositol } \\
18 \text { Mannitol } \\
19 \text { Sorbitol } \\
20 \text { Méthyl-d-mannoside } \\
21 \text { Méthyl-d-glucoside } \\
22 \text { N acétyl-glucosamine } \\
23 \text { Amygdaline } \\
24 \text { Arbutine } \\
25 \text { Esculine } \\
26 \text { Salicine } \\
27 \text { d(+)cellobiose } \\
28 \text { Maltose } \\
29 \text { Lactose } \\
30 \text { d(+)mélibiose } \\
31 \text { Saccharose } \\
32 \text { d(+)tréhalose } \\
33 \text { Inuline }\end{array}$ & $\begin{array}{l}34 \text { d(+)mélézitose } \\
35 \text { d(+)raffinose } \\
36 \text { Dextrine } \\
37 \text { Amylose } \\
38 \text { Amidon } \\
39 \text { Glycogène } \\
40 \text { Arginine } \\
41 \text { Glucose } \\
42 \text { Teepol } 0,4 \text { p. } 100 \\
43 \text { Teepol } 0,6 \text { p. } 100 \\
44 \text { NaCl } 4 \text { p. } 100 \\
45 \text { NaCl } 6 \text { p. } 100 \\
46 \text { NaCl } 10 \text { p. } 100 \\
47 \text { O.N.P.G. } \\
48 \text { Nitrate de potassium } \\
\text { + glucose } \\
49 \text { Acide pyruvique }\end{array}$ \\
\hline
\end{tabular}

de nos précédentes recherches quant à la survie de ces microorganismes durant leur passage dans l'intestin, et a révélé des aspects entièrement nouveaux quant à la fonction particulière exercée par les cellules lactiques en transit.

La recherche effectuée sur les échantillons de selles de neuf enfants, âgés de 3 à 20 mois, a révélé les faits suivants :

1) Les ferments lactiques du yaourt, qui ne font pas partie de la flore intestinale autochtone (comme il résulte de l'identification des espèces de bactéries lactiques isolées par les selles de contrôle), réussissent à traverser le tube gastro-entérique en demeurant inaltérés, même lorsqu'ils sont administrés sous forme de suspensions de cellules isolées et lavées.

2) Tout au long de leur présence dans le tube intestinal, les ferments lactiques du yaourt manifestent une activité particulière, soit à l'égard de la flore lactique autochtone, qu'ils contribuent à augmenter, évitant ainsi le développement de la flore putréfiante, soit sur la flore bifide, qui s'est révélée statistiquement en forte augmentation. Cela montre donc que cette activité n'est pas seulement liée aux caractéristiques du substrat (tel que le lait coagulé), 
mais qu'elle est également provoquée par les cellules isolées en suspension physiologique.

3) Les espèces lactiques découvertes, outre le $L$. bulgaricus, sont le $L$. acidophilus, le $L$. casei et le $L$. fermenti, ces derniers étant, numériquement, le groupe le plus important.

4) Les streptocoques retrouvés le plus fréquemment appartiennent à l'espèce St. faecium, ainsi qu'à une autre forme microbienne thermophile, qui nous laisse perplexes du point de vue taxonomique, étant donné qu'elle présente les mêmes caractéristiques culturelles que le St. thermophilus, mais avec des caractéristiques de fermentation qui se rapprochent de celles de St. bovis.

La plupart des bactéries lactiques, coques aussi bien que bâtonnets, qui constituent la flore lactique intestinale, présentent diverses caractéristiques communes permettant de les classer dans des groupes taxonomiquement homogènes. En considérant que la flore entérobactérienne ne subit aucune modification importante, l'on constate que le passage des ferments lactiques à travers le tube gastroentérique produit des modifications propres à influencer qualitativement et quantitativement la flore lactique et bifide.

La flore lactique et bifide ainsi modifiée révèle des analogies surprenantes avec les modèles jugés optimaux, que l'on retrouve normalement dans l'intestin du nourrisson nourri intégralement au sein, c'est-à-dire dans des conditions physio-alimentaires idéales et plus à l'abri des pollutions secondaires.

\section{Rés um é}

Dans cette étude, les auteurs ont confirmé les résultats de leurs précédentes recherches sur la survie des ferments lactiques du yaourt ( $L$. bulgaricus et $S t$. thermophilus) durant leur passage dans les intestins, en faisant ressortir la fonction particulière des cellules lactiques en transit, même lorsqu'elles sont administrées sous forme de suspensions de cellules lavées.

L'analyse statistique des déterminations micro-biologiques, effectuées sur les selles de neuf enfants, âgés de 3 à 20 mois a révélé que, durant le passage des cellules lactiques, il se produit une augmentation de la flore lactique autochtone (mésophile : $\mathrm{P}=0,025$ et thermophile : $P=0,01$ ) et de la flore bifide ( $P=0,025$ ), et ce, d'une façon statistiquement importante.

Les espèces lactiques trouvées sont représentées par $L$. acidophilus, L. casei et, surtout, par L. fermenti, St. faecium, St. lactis, ainsi que, durant le traitement, par L. bulgaricus et St. thermophilus. 


\section{S u m m a r y}

STUDY ON THE VARIATIONS OF THE INTESTINAL LACTIC AND BIFID FLORA

IN CONNECTION WITH ADMINISTRATION OF LACTIC YOGURT CELLS

In this paper the authors reconfirm the results of their previous researches on the survival of lactic acid bacteria in yogurt ( $L$. bulgaricus and $S t$. thermophilus) during intestinal transit; they stress the specific function of the lactic cells even when they are administered as suspensions of washed cells.

The results of statistical analysis of the microbiological essays on the faeces of nine children aged between three and twenty months, demonstrated that during the transit of the lactic cells a statistically significant increase takes place of the lactic autochthonous flora (mesophile: $\mathrm{P}=0.025$ and thermophile: $\mathrm{P}=0.01$ ) and of the bifid flora $(P=0.025)$.

The lactic species found are: L. acidophilus, L. casei and especially L. fermenti; St. faecium, St. lactis and during treatment also L. bulgaricus and St. thermophilus.

Reçu pour publication en septembre 1977.

\section{Références bibliographiques}

[1] FESCE (A.) (1975). - Rapporto tra ospite e microrganismi intestinali. XVII Congr. Inter. Società Italiana di Microbiologia, Padova, 1975, 1, 129-146.

[2] Anderson (C. M.), Challacombe (D. N.), Richardson (J. M.) (1974). - The Normal flora of Man. Ed. Skinner F. A. \& Carr J. G., Academic Press London, 197-203.

[3] Drasar (B. S.), Hill (M. J.) (1974). - The Normal flora of Man. Ed. Skinner F. A. \& Carr J. G., Academic Press London, 187-195.

[4] Bianchi-Salvadori (B.), Brughera (F.), Salvadori (P.) (1967), - Studio sulle variazioni coprocolturali nel lattante in rapporto alla somministrazione di yogurt. Minerva Dietologica, 7 (3), 176-180.

[5] Salvadori (P.), Bianchi-Salvadori (B.) (1973). - Studio sulle variazioni coprocolturali nell'uomo in rapporto alla somministrazione di yogurt. Minerva Dietologica, 13 (1), 8-12.

[6] Rocchietta (M. S.) (1973). - Studi sulla flora intestinale dei lattanti, alimentati con batteri lattici. Tesi di Laurea.

[7] Premi (L.) (1974). - I Fermenti lattici nella normalizzazione della flora intestinale di giovani animali. Rassegna Clinico Scientifica, 50 (4).

[8] Mayer (J. B.), Keschawarzi (S.) (1970). - The stool flora of infants fed various proprietary infant foods. Medizin Ernährung, 11 (12), 279-282.

[9] Percy-Robb (I. W.), Collee (J. G.) (1972), - Bile acids a pH dependent antibacterial system in the gut? British Medical Journal, 3, 813.

[10] Buttiaux (R.), Beerens (H.), Tacouet (A.) (1969). - Manuel de techniques bactériologiques. Ed. Médicales Flammarion, Paris. 
[11] Paule (R.) (1971). - Contribution à l'étude biochimique du genre Lactobacillus par une méthode normalisée. Thèse Lyon.

[12] De Mann (J. C.), Rogosa (M.), Sharpe (M. E.) (1960). - A medium for the cultivation of Lactobacilli. J. Appl. Bacteriol., 87, 49.

[13] Politi (I.) (1969). - Ricerche sui fermenti lattici della specie St. thermophilus. Ann. Microbiol., 15, 33-56.

[14] Bonomi (U.), Cavalieri (S.) (1974). - Rilievi sulla flora anaerobia intestinale in bambini trattati con Lattobacilli liofilizzati. Rassegna Clinico-Scientifica, 50 (4).

[15] Mossel (D. A. A.) (1962). - Use of a modified Mac Conkey agar medium for the selective growth and enumeration of Enterobacteriaceae, 84, 381.

[16] Renko (P.) (1939). - Microbiologia del latte e dei latticini. Ed. U. Hoepli, Milano, 707.

[17] Cours C.E.R.B.A., 1969.

[18] Scardovi (V.), Trovatelli (L. D.), Zani (G.), Crociani (F.), Matteuzzi (D.) (1971). - Deoxyribonucleic acid homology relationship amon species of the genus Bifidobacterium. Int. J. Systematic Bact., 21 (4), 276-294. 